\title{
A case of extensive symptomatic lower limb heterotopic ossification in a boy
}

\author{
Inez Kartika, ${ }^{1}$ Elysanti Dwi Martadiani, ${ }^{1}$ I Gede Eka Wiratnaya, ${ }^{2}$ I Wayan Juli Sumadi ${ }^{3}$
}

pISSN: 0853-1773 • elSSN: 2252-8083 https://doi.org/10.13181/mji.v28i4.2633

Med J Indones. 2019;28:386-90

Received: May 2, 2018

Accepted: August 20, 2019

\section{Authors' affiliations:}

'Department of Radiology, Faculty of Medicine, Universitas Udayana, Sanglah Hospital, Bali, Indonesia, ${ }^{2}$ Department of Orthopaedic Surgery, Faculty of Medicine, Universitas Udayana, Sanglah Hospital, Bali, Indonesia, ${ }^{3}$ Department of Anatomical Pathology, Faculty of Medicine, Universitas Udayana, Sanglah Hospital, Bali, Indonesia

\section{Corresponding author:}

Inez Kartika

Department of Radiology, Faculty of Medicine, Universitas Udayana, Sanglah Hospital, Jalan Diponegoro, Denpasar 80113, Bali, Indonesia

Tel/Fax: +62-361-229711 ext. 384/

$+62-361-224206$

E-mail: inez.kartika@yahoo.com

\begin{abstract}
Heterotopic ossification refers to the abnormal growth of bone in the soft tissue. This report highlighted the case of heterotopic ossification in early childhood. A 3-year-old boy was presented with poor lower limb mobility and rigid left leg. At the age of 10 days, he developed a small lump as large as a quail egg in his left groin. Within 3 months, the lump grew bigger and spread to his leg and feet. His parents claimed no trauma history. It was confirmed by computed tomography scan which revealed multiple ossifications of the soft tissue infiltrating the lower limb muscles and infiltrating the skin, the pathological features showed hard mature trabeculated bone, mature fatty tissue, and loose connective tissue. The patient was treated with a series of soft tissue resections and was still under the care of surgeon with good prognosis.
\end{abstract}

KEYWORDS heterotopic ossification, pediatrics, radiography
Heterotopic ossification refers to the abnormal growth of bone in the soft tissue. This abnormal ossification causes bone deformation, loss of range of motion (ROM), and joint immobility. ${ }^{1,2}$ The mechanism is not completely understood, although a previous study demonstrated heterotopic ossification may derive from mesenchymal cells that transform to osteocytes. ${ }^{1}$ Mesenchymal cells, including in the soft tissues are potential to differentiate into osteogenic cells with appropriate stimuli under appropriate environment. ${ }^{2}$ This case is extremely rare in the pediatric population and almost unheard of in newborns.3,4 This case report highlighted the clinical and radiological features of heterotopic ossification in early childhood.

\section{Case report}

A 3-year-old boy was presented with poor lower limb mobility and rigid left leg; he was unable to walk properly and unable to extend his left lower leg. The complaint was begun at the age of 10 days with quail egg sized lump in his left groin. The lump was growing slowly, but within three months, the lump had rapidly grown bigger, and several lumps had also 


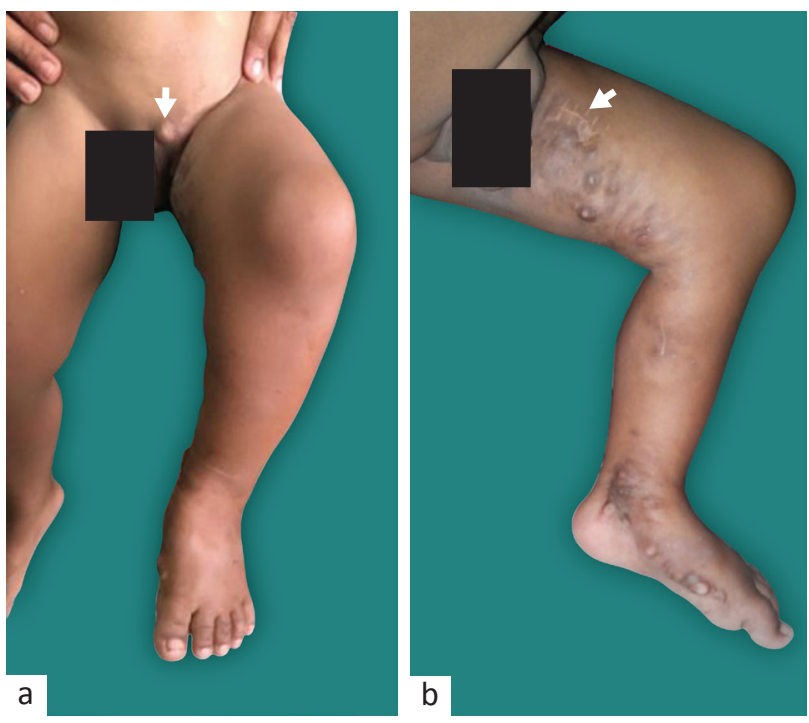

Figure 1. Clinical features of left leg at the first examination. (a) Left inguinal lump (white arrow); (b) multiple small lumps, located in the medial left thigh, medial left leg, and left foot. There was a scar on a lump's surface due to previous lumpectomy (white arrow). The knee joint was always in the $90^{\circ}$ flexion position causing fixed flexion deformity

developed along his left leg and foot. His lower knee joint gradually fixated in $90^{\circ}$ flexions and this caused an inability to stand up straight. He was only able to crawl. Before the parents took him to this hospital, they had asked local paramedic to remove the lump in the left thigh. The paramedic only removed one lump and no further examination was done. Since then, he had not treated because of the accessibility of health care facility and parents' unawareness of the disease. During pregnancy, his mother did not do routine antenatal care. The boy was born through vaginal delivery and his parents claimed no history of trauma.

On the first examination, his vital signs were normal. Physical examination revealed a hard lump in the left inguinal region of about $4 \times 2 \mathrm{~cm}^{2}$ and fourteen smaller lumps of $1 \times 1 \mathrm{~cm}^{2}$ in size scattered in the medial left thigh until the medial left leg and left foot. All the lumps had a lighter skin tone than the surrounding skin; were painless, immobile, and well-defined (Figures $1 a$ and 1b). There was a scar on the surface of left thigh because of previous lumpectomy by local paramedic (Figure 1b). The soft tissue at the inner leg hardened and stiff like a plank of wood with limitation in the ROM. His knee joint fixated in $90^{\circ}$ flexions and could not be straightened. The length between both legs were equal, but muscle atrophy was noticeable on the left leg. His sensory examination was within normal limits with no pathological reflexes. A laboratory examination (complete blood count, kidney function tests, and liver function tests) revealed normal results. The authors had obtained informed consent from the patient's parent and guardian to publish a part of the patient's body and his medical examination results. Confidentiality of the patient's identification was maintained in this manuscript.

X-ray of the left lower limb demonstrated a wide amorphous soft tissue ossification at the inner aspect of the left thigh, left leg, and left foot, with normal trabeculation and no erosion or destruction
Figure 2. Plain x-ray of the left lower limb at the first examination. A wide amorphous ossification of soft tissue (white arrow) at the medial aspect on the: (a) left thigh; (b) left leg, and (c) left foot, with normal trabeculation and no erosion or destruction of the bone, raising the suspicion for heterotopic ossification
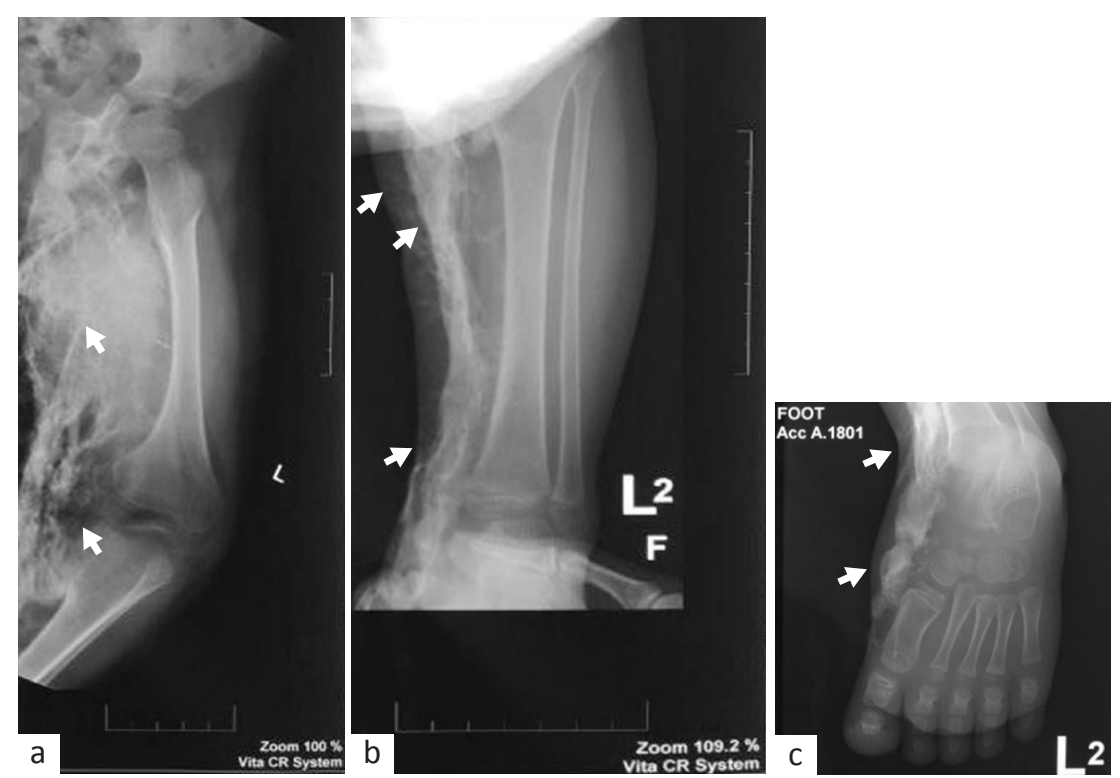

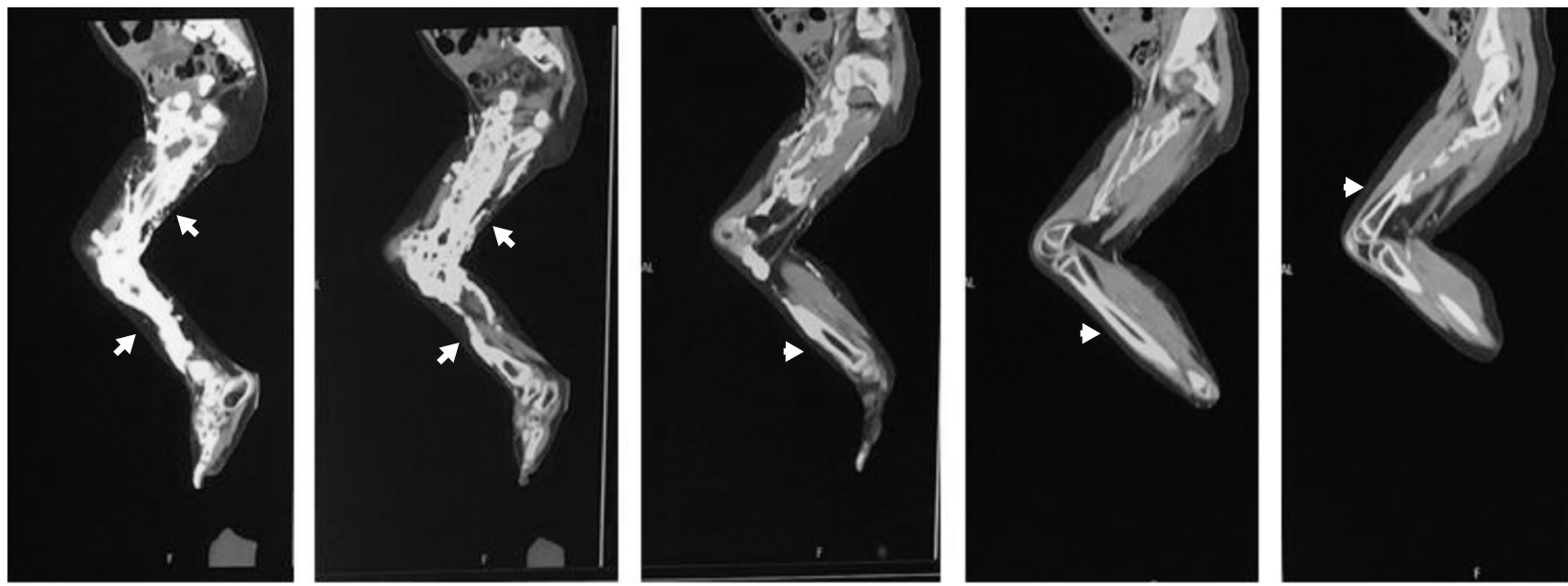

Figure 3. Sagittal reformat from computed tomography scan of the left leg showing soft tissue mass with calcification (white arrow) from the left thigh until the leg and infiltration to the left obturator muscle, adductor longus muscle, gluteus maximus muscle, sartorius muscle, quadriceps muscle, gastrocnemius muscle, and soleus muscle. It also infiltrated the skin and the subcutaneous layer around it and encased the left femoral and iliac artery and vein. No bone erosion from the ossification (white arrowhead)

of the bone, raising the suspicion for the presence of heterotopic ossification (Figure 2).

A computed tomography (CT) scan of the left lower limb revealed multiple ossifications of the soft tissue infiltrating the left obturator muscle, adductor longus muscle, gluteus maximus muscle, sartorius muscle, quadriceps muscle, gastrocnemius muscle, and soleus muscle and also infiltrating the skin and the subcutaneous layer around it. There was also mass encasement of the left femoral and iliac artery and vein (Figure 3). Neither bone erosion nor destruction was observed, and bone trabeculation was also within the normal range.
The patient underwent surgery for removing the mass from the leg's soft tissue (Figure 4). During the surgery, the pathological tissue can be visually seen from the normal tissue macroscopically, but when the excision was done, the normal muscle tissue was also cut. To avoid this, the surgeon a gradual resection and a series of operations was planned to achieve better muscle tissue reservations. The multiple hard white masses were resected (Figure 4b). Histopathological examination revealed a mature trabeculated bone, mature fatty tissue, loose connective tissue, and blood vessel confirming heterotopic ossification (Figure 4c).
Figure 4. Site of surgery and histopathology. (a) The resected area at the medial aspect of the left leg; (b) whitish masses collected from resection; (c) mature trabeculated bone (black arrow), mature fatty tissue, loose connective tissue of histopathology under 100 × magnification; (d) a striking feature of heterotopic ossification (black arrow) under $400 \times$ magnification. Histopathological examination was stained with hematoxylin and eosin
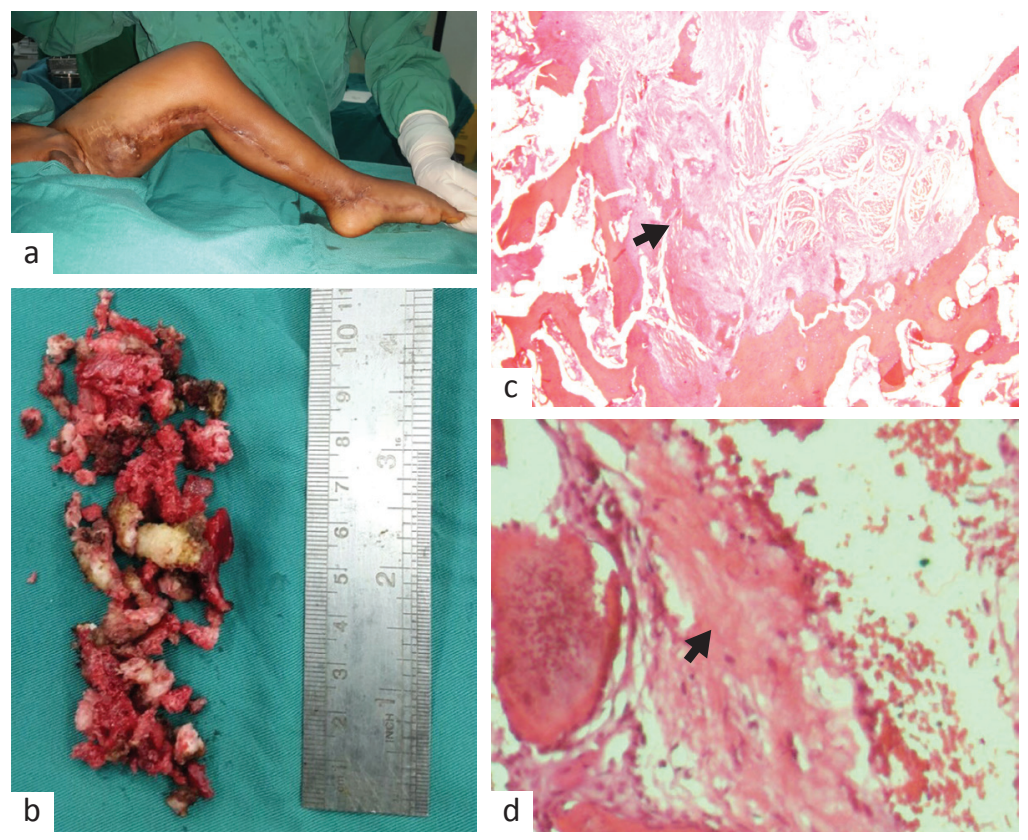
Figure 5. Follow-up imaging after the third resection showed a significant reduction in ossification in the: (a) inner left thigh (white arrow) and (b) leg (white arrow)
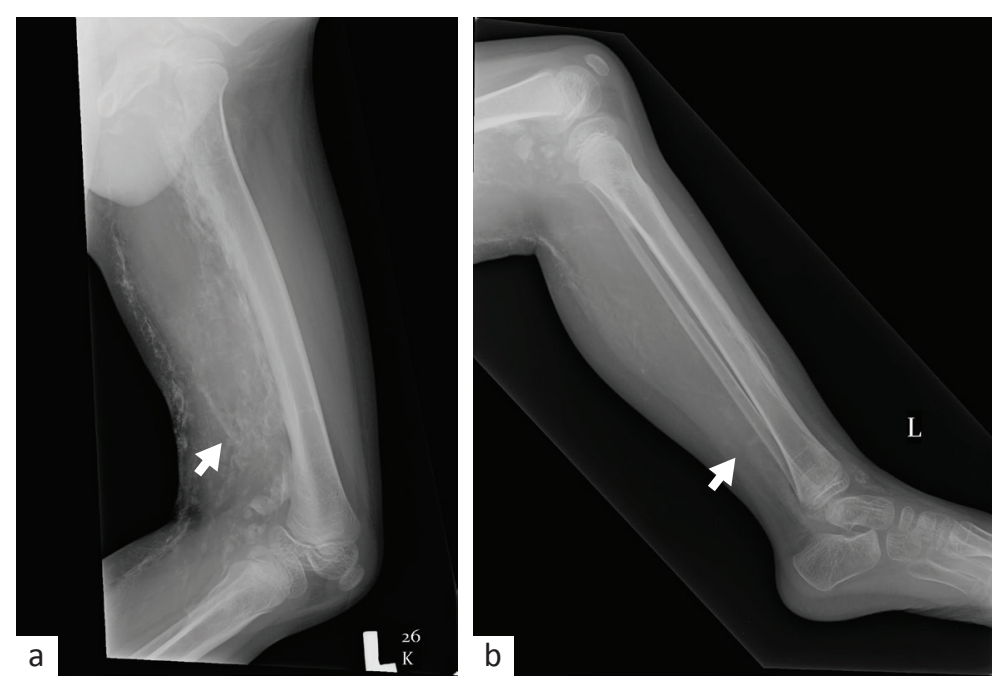

After 3 months of the first resection, there was improvement in the knee's ROM but it was still limited. Further $\mathrm{x}$-ray of left lower limb demonstrated fewer and smaller amorphous soft tissue ossifications. Second and third resections were performed with an interval of three months to provide sufficient time for the growth of the normal muscle and to maintain muscle density. The last $x$-ray of left lower limb after the third surgery revealed minimal amorphous ossification of the soft tissue at the inner aspect of the left thigh, left leg, and left foot (Figure 5). The patient continued his physiotherapy to walk properly.

\section{DISCUSSION}

Heterotopic ossification is the formation of mature lamellar bone in soft tissues. It forms outside the joint capsule and periosteum. ${ }^{5}$ Diagnosing heterotopic ossification in children is difficult, since it is rare among children. We only found two published case reports from Koch et $\mathrm{al}^{3}$ and Khoo et $\mathrm{al}^{4}$ that have confirmed a rare episode of heterotopic ossification in the pediatric population, but in those cases, all patients had previous trauma or burn injury. Heterotopic ossification has no pathognomonic clinical feature. The patient would only complain of a limitation in ROM without any specific signs such as inflammation and masses. ${ }^{6}$

The pathogenesis of heterotopic ossification is yet to be made clear. ${ }^{5}$ Heterotopic ossification develops through the formation of a bone cell (osteoid) that is eventually calcified, remodeled, and matured into a well-organized trabecular bone. These bony lesions have a high metabolic rate, adding new bone at more than three times the rate of normal bone. ${ }^{7}$ The pathological bone may be found in the muscle or soft tissue which is shown in this case report.

In this case, the patient had no prior trauma nor a similar family history. The complaint was only the growth of lumps in the left limb from the inguinal region to his feet, followed by the hardening of soft tissue mass and contracture of the knee joint. The differential diagnosis of this complaint was primary bone malignancy or infection. X-ray of the left leg would help the diagnosis.

Plain x-ray is preferred for initial assessment for musculoskeletal problem. It is recommended in all patients suspected heterotopic ossification in order to know the bone pathology. ${ }^{8}$ The radiological features in this case were highly suggestive of heterotopic ossification. CT scan supported the diagnosis of heterotopic ossification and histopathological examination confirmed the diagnosis. The ossification might be seen in radiograph up to six weeks. ${ }^{8}$

Two studies examined the prophylactic therapy by administering anti-inflammatory drugs after spinal cord injury to reduce the development of heterotopic ossification. They used rofecoxib $25 \mathrm{mg}$ daily for 4 weeks 9 and indomethacin $75 \mathrm{mg}$ daily for 3 weeks. ${ }^{10}$ However, rofecoxib is no longer used because of its adverse cardiovascular effect. ${ }^{7}$

Until now, there is no definite treatment for heterotopic ossification and it remains a challenge. It can only be treated surgically once the ossification has matured. ${ }^{11}$ Surgical removal for heterotropic ossification is not similar as in oncologic cases which need radical resections. It only needs to remove ossifications which cause mobility limitation and 
vascular or nervous compression. ${ }^{12}$ In this case, the resections were performed gradually with three months interval in order to provide sufficient time for the muscle growth and to maintain muscle density. Two previous reports state that the goal of surgery is to restore joint motion completely, to release nerves and vessels, and to maintain adequate tissue perfusion. ${ }^{12,13}$ Capsulectomy of the joint is sometimes needed in some cases with intra-articular stiffness caused by cartilage degeneration and fibrosis, ${ }^{13}$ but in this case it was limited to extra-articular tissue.

Physiotherapy was needed to limit the stiffness after the resection. ${ }^{8}$ It focused on the movement of the lower limb to avoid muscle stiffness by ROM exercise and stretching. ${ }^{14}$ Stretching increases muscle length, ROM, and more muscle fiber. In this case, the physiotherapy showed good outcome as shown in the improvement of the knee's ROM. Proactive physiotherapy management team may give good results as shown in the previous cases. ${ }^{15}$

\section{Conclusions}

In this case, we want to show that early diagnosis of heterotopic ossification is important for minimizing deformity and ankylosing. Radiological examinations provide essential information in the initial investigation of heterotopic ossification in pediatric cases; therefore, good recognition and comprehensive treatment of pediatric heterotopic ossification need to be done as soon as possible to avoid disability.

\section{Conflict of Interest}

The authors affirm no conflict of interest in this study.

\section{Acknowledgment}

None.

\section{Funding Sources}

None.

\section{REFERENCES}

1. Schuetz P, Mueller B, Christ-Crain M, Dick W, Haas H. Aminobisphosphonates in heterotopic ossification: first experience in five consecutive cases. Spinal Cord. 2005;43(10):604-10.

2. Pape HC, Marsh S, Morley JR, Krettek C, Giannoudis PV. Current concepts in the development of heterotopic ossification. J Bone Joint Surg Br. 2004;86(6):783-7.

3. Koch BM, Wu CM, Randolph J, Eng GD. Heterotopic ossification in children with burns: two cases reports. Arch Phys Med Rehabil. 1992;73(11):1104-6.

4. Khoo SS, Felix LY, Azura L, Manmohan S, Jeffry A. A rare case of heterotopic ossification in a newborn: a case report. Malays Orthop J. 2012;6(3):48-50.

5. Patil SG, Siddiqua A, Joshi UK, Deshmukh PK, Patil BS, Mangalgi A. Heterotopic ossification: an unusual presentation. Case Report Dent. 2012;2012:516717.

6. Hsu JE, Keenan MA. Current review of heterotopic ossification. UPOJ. 2010;20:126-30.

7. Teasel RW, Mehta S, Aubut Jl, Ashe M, Tu L. Heterotopic ossification following spinal cord injury. In: Eng JJ, Teasell RW, Miller WC, Wolfe DL, Townson AF, Hsieh JTC, et al., editors. Spinal cord injury rehabilitation evidence. Version 3.0. Vancouver: SCIRE Project; 2010. p. 1-13.

8. Barlaan PI, Ip WY. Heterotopic ossification in the middle finger: a case report. Case Rep Orthop. 2011;323795.

9. Banovac K, Williams JM, Patrick LD, Levi A. Prevention of heterotopic ossification after spinal cord injury with COX-2 selective inhibitor (rofecoxib). Spinal Cord. 2004;42(12):707-10.

10. Banovac K, Williams JM, Patrick LD, Haniff YM. Prevention of heterotopic ossification after spinal cord injury with indomethacin. Spinal Cord. 2001;39(7):370-4.

11. Predescu V, Olaru R, Prescura C, Deleanu B. Rare and disabling heterotopic ossification: a case report. Arch Med. 2015;7(4):1.

12. de l'Escalopier N, Salga M, Gatin L, Genêt F, Denormandie P. Resection of heterotopic ossification around the hip after trauma. EFORT Open Rev. 2019;4(6):263-8.

13. Sorriaux G, Denormandie P, Martin JN, Kiefer C, Judet T. Excision of heterotopic new bone around the elbow in patients with head injury: 51 cases. Rev Chir Orthop Reparatrice Appar Mot. 2005;91(5):415-22. French.

14. Page P. Current concepts in muscle stretching for exercise and rehabilitation. Int J Sports Phys Ther. 2012;7(1):109-19.

15. Knight LA, Thornton HA, Turner-Stokes L. Management of neurogenic heterotopic ossification: three case histories to illustrate the role of physiotherapy. Physiotherapy. 2003;89(8):471-7. 